\title{
Linguistic Patterns in English Versions of Tao Te Ching Reflect British Politics from 19th to 20th Century
}

\author{
Chen $\mathrm{Gao}^{1, \dagger}$, Xiatong $\mathrm{Li}^{2, \dagger}$, Peiyun $\mathrm{Wu}^{3, *}, \dagger$ \\ ${ }^{1}$ Tianjin Foreign Languages School, Tianjin, China \\ ${ }^{2}$ United World College Changshu China, Suzhou, Jiangsu, China \\ ${ }^{3}$ School of English and International Studies, China Foreign Affairs University, Beijing, China \\ ${ }^{*}$ Corresponding author.Email: wupeiyun@mail.cfau.edu.cn \\ ${ }^{\dagger}$ Those authors contributed equally.
}

\begin{abstract}
Foreign translations of the Tao Te Ching, one of the Chinese classics, are faced with the dilemma of how to provide a more relevant interpretation of the original text. Research has shown that differences in the interpretation of the same content are influenced by a variety of factors rooted in society, culture, personal beliefs, and personal experience. The aim of this study is to analyse the varying impact of differences in political stance on the language patterns used in the translation process. Based on a review of the currently approved literature on content descriptions and further analysis by Chinese scholars Chen Guying and Lin Yutang, their interpretations are compared with the introduced English versions. Three chapters (57, 60 and 65) showing the idea of 'nothingness', the idea of a return to truth and the presumed correct attitude to the relationship between man and God have been chosen as representative of a political thought based on Chinese culture. A comparison of textual interpretations indicates that changing political factors contribute to different tendencies to interpret the same content. The results suggest that political factors do have an impact on the interpretation of foreign literature.
\end{abstract}

Keywords: Tao Te Ching, Translation, Non-action, Religious.

\section{INTRODUCTION}

The Tao Te Ching is an important work by Lao Tzu, demonstrating a unique Chinese vision from man to the universe. It is a famous Taoist classic that has influenced the whole history of the West and China. This work was written during the Spring and Autumn period when wars were frequent, society was in chaos, power was alternating between states and people were displaced. As such, Laozi describes in this book a solution to a practical problem with a focus on nature and non-action.

Over the centuries, the Tao Te Ching has been widely translated into different languages. These translations show not only the different understandings of the work, but also the influence of the political context on scholars. Religion has made a huge difference in the different interpretations of the Tao Te Ching. The degree of religious freedom in a society and the political attitudes of its rulers also influenced the religious component of the writing and the translation of different versions. Therefore, this paper will analyse the varying impact of differences in political stance on the language patterns used in the translation process.

In this essay we will focus primarily on two English versions by Frederic Henry Balfour and James Legge. It begins with an introduction to the translation strategies used by Lin Yutang and John Minford, which are known as Lectio Divina, foreignisation and thick translation. The paper will also present the cultural interpretations inherent in the Tao Te Ching. In addition, we will explain the chapters of the Tao Te Ching that we have chosen to represent $\mathrm{Wu}$ Wei, Divine and Obscurantist respectively, and the reasons for their selection. We will then introduce the translators of the two translations and their backgrounds. The different translations are then compared together, with the version by the Chinese translator Chen Guying as a sample, and the different understandings are further discussed. This is followed by an exploration of how political factors, including the social context and the attitudes of the rulers, influence the interpretation of the work. 


\section{LIN YUTANG \& JOHN MINFORD'S TRANSLATION STRATEGIES FOR TAO TE CHING}

John Minford utilizes the Lectio Divina combined with the translation method of Nouvelle Chinoiserie to compactly express the original meaning of Lao Tzu. Lectio Divina is the process containing reading, meditation, prayer, and contemplation, Minford interpreted the text through the "energy from emotion" and his life experience. For example, he adds his thought in the fourth chapter's note: "I am the Tao. I was here before the Emperors of Old, before Heaven and Earth. I have been here forever, in Stillness, Not Contending." Minford employs the compact form and simple lexicons, which style is called Nouvelle Chinoiserie to represent ideas obtained from Lectio Divina, in the fifth chapter, he translated that: "The Five Colors/ Blind the eyes/ The Five Sounds/ Deafen the ears." [1] The style of Minford's version is brief and abstract; the cultural context is lacking, although it efficiently translates the content of Tao Te Ching.

Lin Yutang utilized two main translating approaches entailing foreignization and thick translation in the 1948 English version of Tao Te Ching. Diao Yanhui introduces that Lin utilized foreignization to expand the vague classical Chinese expressions for helping readers accept the text, for example, he translated "living in a kind place" into "in his dwelling, the sage loves the lowly earth." Foreignization was combined with the thick translation theory, which refers to "a translation that seeks with its annotations and its accompanying glosses to locate the text in a rich linguistic and cultural background." [2] The research paper Lin Yutang's thick translation of Lao Zi's Wisdom divides Lin's translation into internal and external parts. The author argues that: "for internal text, thick translation fall into explanation within text, descriptive translation, approximate translation as well as calque." For the external text, Lin Yutang "provides a variety of linguistic and cultural background information covering the brief introduction to the philosophical background on Taoism and the translator's intention as well as the translation features." [3] Overall, Lin Yutang's English version of Tao Te Ching not only preserves the original meaning of Lao Tzu but also effectively illustrates related cultural context.

\section{EXPLAIN NON-DOING, HUMAN AND DEITIES \& OBSCURANTISM THROUGH THE PERSPECTIVE OF CHEN GUYING}

This study selects chapter 57 as the sample passage for examining the difference in comprehension from two translators to the non-action thought in Tao Te Ching. Non-action argues that everything should develop itself under its unique condition, and nothing outside should get involved putting influence on it. Governors are required to respect the lifestyle of people and try not to intervene how it originally was. In this chapter, Lao Tzu cautions hazards resulting from commanders' interference to the nation, for instance: " the more prohibitions there are, the poorer the people become. The more sharp weapons there are, the more prevailing chaos there is in the state." [4] Lao Tzu establishes dualism that the encouragement to brightness and kindness will activate darkness and evilness to grow, since clarifying the definition of justice will inevitably involve the meaning of injustice.

Chapter 60 is being considered as the sample passage for investigating the various interpretations from two translators to lao tzu's thoughts about the relationship between humans and deities. Lao Tzu stressed that governing a large country is like frying a small fish, indicating that exercising governance should be quiet and inactive and that disturbance could harm the people. Using this ideal-governance idea, Lao Tzu put forward his idea of paying attention to what people have done instead of lining on ghosts and gods. That is, calamity is the result of people's choices and actions. If people can do their jobs well enough, then there would be no disaster happen. This thinking manifests the ideas of weakening the stress on the role of god, instead, pulling the focus back onto man's capability. In addition, this concept happens to have the same view as Confucius' idea of focusing on the deeds of men, yet later a bit disguised by the notion of the divine right of kings through which they strengthen their power.

Chapter 65 states the crucial idea of obscurantism, which generally refers to a policy of withholding knowledge from the general public, but here Lao Tzu means that rulers should encourage people to be simple, not to learn petty tricks. The original text depicts that: "The Ancients who knew how to follow the Tao Aimed not to enlighten the people, But to keep them ignorant. The reason it is difficult for the people to live in peace is because of too much knowledge." Lin Yutang in the footnote annotated that the "knowledge" indicates the "lower forms of knowledge" which were "used for selfish end", the prevalence of this kind of knowledge causes "civilizations decay and may destroy themselves." [5] With the elimination of a lower form of knowledge, "things revert back to their source, then and then only emerges the Grand Harmony." Lao Tzu in this chapter appealed to people to follow the kind nature of humans and abandon the desire of fighting to each other, therefore, we consider this passage as the representative sample of obscurantism. 


\section{INTRODUCTION TO SAMPLE ENGLISH VERSIONS OF TAO TE CHING FROM FREDERIC HENRY BALFOUR \& JAMES LEGGE}

Chapter 57, 60, and 65 in English versions from Frederic Henry Balfour and James Legge are chosen as the sample passage for perceiving the difference in linguistic patterns, and correlating the results to the historical events, answering the research question of "how does the linguistic patterns in past English versions of Tao Te Ching reflect the political features and changes from 19 century to 20 century?"

The translator of the translated version of Taoist Texts is Frederic Henry Balfour who is religious, philosophical, and has a deep understanding of Chinese culture. Frederic Henry Balfour was a British author who was famous for his work "Taoist Texts: Ethical, Political and Speculative", also known simply as Taoist Texts in 1884. Frederic Henry Balfour has always been a very prolific and religious writer. He has created many works about the influence of theism on modern society. At the same time. He has lived in Shanghai and worked in many newspapers in China, including North China Daily News, The Shanghai Evening Courier, and The Celestial Empire newspapers during the Victoria era. His working and life experience shaped his deep understanding of Chinese culture [6].

The year when this version is published, Britain is still under the monarch of Victoria when people are increasingly pursuing romanticism and mysticism. In addition, at that time, Britain had an amazing number of innovations in various fields and became a symbol of the British national level at that time. Also, the relationship between Britain and other countries except Russia is relatively mild.

Sacred Books of the East is another translated version of Tao Te Ching written by James Legge, a missionary in London and also the first Chinese professor in Oxford. Same as John Chalmers James Legge is also a missionary in Protestantism. As a missionary to China, he had lived in Hong Kong for more than 30 years as a professor teaching AngloChinese. Convinced of the need for missionaries to be able to comprehend the ideas and culture of the Chinese, he began in 1841 a translation in many volumes of the Chinese classics. All his translations were done together with the help of two Chinese: Wang Tao and Hong Rengan. Therefore, compared with the other author, James had a very comprehensive understanding of Chinese culture and combine Chinese perspectives while translating [7].

\section{COGNITIVE DIFFERENCES BETWEEN GHOSTS AND GODS AND THE RELATIONSHIP BETWEEN THEM AND TAO IN CHAPTER 60}

Frederic Henry Balfour and James Legge both believe that "ghost" is the soul of a person who once existed in reality. In Taoist Texts, Frederic Henry Balfour translated "ghost" as "the spirits of the departed" [6]. In Sacred Books of the East, James Legge described "ghost" as "the manes of the departed". This shows that they do not think "ghost" is a concept of nothingness, but more a spiritual carrier of a real body after death. And "ghost" is not necessarily derogatory, it is an individual symbol, so it is a neutral noun [7]. However, according to Chen Guying's annotation, "ghost" in ancient China refers to the product of "excess Yin in the Yin and Yang of the eight trigrams". [4] In the Chinese concept, "ghost" is a completely illusory concept. It is a concept without a real reality carrier.

At the same time, the two versions have different views on the manifestation of "ghost". Taoist Texts believe that the process of "ghost" becoming "god" is how "ghost" appears. This shows that he believes that there is no obvious boundary between "ghost" and "god". This also shows that he still believes that "god" is higher than "ghost", because he believes that the process from "ghost" to "god" is an embodiment of externalization and a kind of progress. He also weakens the divinity of "god", which is not out of reach, but a practical carrier [6]. In contrast, the description of the emergence of "ghost" in Sacred Books of the East refers to "spiritual energy". He believes that after the emergence of "ghost", it still appears as the noumenon of "ghost", but its energy is enhanced [7].

\subsection{Different interpretations of "God"}

The two versions also have different understandings of "God". Taoist Texts compare "God" to "the gods of the land" [6]. However, in Sacrad Books of the East, James Legge believes that "ghost" and "God" are essentially the same, and there is no difference. Their good and evil nature is the same [7]. According to his previous understanding, of "ghost", so the essence of "God" also has the real body as the carrier, rather than completely overhead. However, according to Joseph Shih, "God" in the spring and Autumn period of China refers to the "emperor" itself, and the "emperor" is the specific carrier of "God". However, at that time, people did not think that the "emperor" was also a real person. "God" still maintains its abstract meaning. It contains the people's yearning for a better life at that time [8]. In China, "God" is "good" and is separated from real life and has no carrier in reality. 


\subsection{Different interpretations of "When both do not do each other harm, The original character is restored."}

The understanding of the last sentence in the two versions is contrary to that of Chinese translators. Taoist Texts and Sacred Books of the East both translated the meaning of the last sentence into "when Gods and sage don't hurt each other, their virtual can be integrated." [4][6] but this is a deviation from the original Chinese meaning. According to Chen guying's annotation and translation, "When both do not do each other harm" means "when Gods and saints don't hurt people". "xiang" here expresses not "mutual" but "towards". At the same time, the object of harm is omitted in this sentence, that is, "the people". Therefore, the sentence ", The original character is restored" should express "so that the people can get virtue". Chen guying's version reflects that he believes that there are differences and boundaries between "the people" and "ghost and "Gods" [4]. Taoist Texts and Sacred Books of the East believe that" ghosts and Gods "have a carrier of reality and are still a part of reality [4][6]. Their understanding is contrary to that of Chinese philosophers.

\section{LAO TZU'S THINKING OF NON- ACTION IN CHAPTER 57}

The first sentence of this chapter focuses on governing a nation, applying the military, and obtaining the universe. The understanding of this sentence has discrepancies between the two chosen versions and the one interpreted by Chinese scholar Chen Guying. Looking through these two versions of translation, Frederic Henry Balfour and James Legge showed different focus in interpretation--the former attributes all the responsibilities on a highly-restricted group--the cultivator of Tao, yet the latter make the three events to be independent with each other and avoid using a single subject to claim all these duties. To govern a nation, in this chapter written as "Rule a kingdom by the Normal.", from Chen Guying's version of interpretation, "Normal" here means the way of quietude without any greedy desire [4]. Yet Frederic Henry Balfour and James Legge both have different comprehension on this. For Frederic, "Normal" can be comprehended as a strategy in governing with uprightness, emphasizing the quality of the dictator [6], while James uses "measures of correction" for interpretation, paying more attention to the method for governance [7]. In translating "Fight a battle by tactics of surprise."--the strategy of applying troops, the main difference is shown in how "surprise" is elaborated in the chosen versions. From Chen, "surprise" reflects the importance of adjusting one's position according to the ever-changing situation [4]. Yet Frederic explained this idea through acquiring exceptional sagacity [6], while James stressed the use of crafty dexterity [7]. Lastly, in line with Chen Guying's annotation, "Win the world by doing nothing." means "governing the universe through non-interruption". [4] "by doing nothing" here is to add no excessive disturbance to people's lives, yet not a thorough indulgence. Frederic used "inaction" to illustrate this notion but narrowed the scope of influence for applying this idea into an empire [6], while James, on the other hand, used "freedom from action and purpose" for the explanation with a better understanding of Lao Tzu since it gets no restrictions in the audience of the mentioned measure compared with the previous [7].

As for the interpretation of the last paragraph, Frederic Henry Balfour and James Legge showed a similar preference in illustrating Lao Tzu's ideal society in the last paragraph. Yet there are still discrepancies between these two versions of translation. In describing "do nothing", here in this article explained as "nonaction", Frederic explains this notion as "do nothing" [6] while James added "on purpose" at the end of this phrase [7], thus distinguished to be different and closer to the original meaning. The other notion, "deal in no business", elucidated as an attitude of avoiding interruption in Chen Guying's interpretation [4], is explained as "take no measures" in Taoist Texts: Ethical Political and Speculative, showing the fallacy of understanding of a complete indulgence [6], while Sacred Books of the East does a better job in close-todesigned interpretation using the phrase "take no trouble" [7]. In the final phrase about "no desires", "desires" is explained as greediness by Chen, yet he also he also stresses that "no desires" is never a restriction to the inherent desires [4]. Frederic here also presented a rather unilateral understanding--we can see it from the word choice-- "have no desires" [6]. However, James doesn't catch the whole picture either: he translates this as "manifest no ambition" [7], which cannot equate the actual action and shows little connection with one's true greedy desires.

\section{LAO TZU'S THINKING OF RETURNING TO A GENUINE STATE IN CHAPTER 65 - THE INTERPRETQTION OF "MYSTIC VIRTUE"}

This cited sentence means to make people genuine and simple instead of teaching them to bear themselves with petty tricks from Chen Guying's annotation [4]. Yet in the history of interpretation, this notion has been misunderstood as a policy of obscurantism. Comparing the two chosen English versions, both Frederic and James noted to make people simple rather than enlighten them, however, James further adds at the end of his translation to make people ignorant [7], which unexpectedly corresponds with the prevalent fallacy in the interpretation of this chapter.

The notion of "Mystic Virtue" is repeatedly stressed in Tao Te Ching, getting different interpretations over 
years. While "Virtue" always gets the connotation of virtue, "Mystic" has "mysteriousness" as a prevalent explanation. This illustration has been applied by both Frederic and James in their translations, while they also have a similar interpretation of "and things revert back", mainly the opposition of other objects. Yet Chen Guying offered another way of understanding--a return to simple and genuine with all the things [4]. The reason for the mentioned discrepancy incomprehension is the different decipher of "revert", for it can mean returning and opposing at the same time [9].

\section{DISCUSSION}

\subsection{The concept of "ghost" in Chinese culture}

In China, "ghost" is the symbol of "evil". According to poo $\mathrm{Mu}$ Chou, in China, "ghost" is often accompanied by fear, because people believe that "ghost" is inextricably linked to some unfortunate things. At the same time, people deeply believe in these connections. "ghost" is an abstract image in religion, which carries people's world outlook and philosophy [10].

\subsection{Different views on Gods between China and the West}

The Chinese people are pious and awed of "God", while western missionaries believe that there is no obvious separation between "God" and "God". There is a huge gap in the notion of "God" between China and the West. According to Liu Yu, Western Christian missionaries are often described as "tragedy hero" in China. Chinese people have strong resistance to Western missionaries, so even western missionaries achieved unprecedented results in China in the 17th century. Still unable to change deep-rooted ideas and move to other countries [11]. This opposition between religion and belief has hindered the religious exchange between China and the West for a long time.

Religion and belief are very important factors in the translation of "God". Such religious division and ideological differences lead to differences in translation. What Chen guying embodies is the abstraction of "God" in oriental thought, which is supernatural and has no specific physical carrier [4]. And Frederic Henry Balfour's philosophical theory is close to Socrates. According to Shen Siying, Xie Linjie, they are aware of God. They believe that God is the creator of all things and has the dominion of all things [12]. This explains Frederic Henry Balfour's description of "God" as "the gods of the land" because they believe that the right of "God" and control over land are a large part of the divinity of "God".

\subsection{The relationship between religious color and political change in Translation}

The strong religious color in the two translations is closely related to the religious freedom in the Victorian period. Frederic Henry Balfour and James Legge are both British writers. At the same time, another important feature of them is their strong religious color. According to Zhang Ning, at the beginning of the Victorian period, the Church of England declined, and its power was gradually weakened. On the other hand, this promoted the development of other sects, including Protestantism. At the same time, the attitude of British rulers towards religion has also changed. "Since the 1930 s, with the relaxation of the religious and political environment in Britain, there has been the largest religious revival since the Puritan movement in the 17th century, with many religions in parallel at one time." It is in this extremely free and open environment that individual religious beliefs are well expressed [13]. As mentioned above, it can be seen that the understanding of "ghosts and Gods" in Taoist texts and sacred books of the East is inseparable from the author's own religious beliefs.

\subsection{The construction of Lao Tzu's assumed the ideal political status}

In the last paragraph in chapter 57 , the ideal living condition for people in Lao Tzu's assumption is presented by the words of the saint: a society that the governors try not to make any interruptions in the society and restrict their excessive desires to assure people the freedom of developing themselves and returning to the genuine state. Throughout Tao Te Ching, "saint" has been widely applied, offering the desired example for governors to follow. Lao Tzu appraised the characters of the saint to provide a perfect model of governance. That a sovereign must adopt the measure of Non-action till he could do it with a mindset without any greedy desires, hence can be called a saint [9].

The historical background accounts for different understandings of the same content. Both Frederic and James live in the period during which English accomplished its crest-stage, witnessed the rise of the voice for a further conceding of rights by the government. Hence from their translations, an preference of quitting the government's interruptions and constraining the governor's greediness has been emphasized, as well as the attention of offering people the freedom of self-developing.

\subsection{The notion of "Mystic Virtue" in politics}

The notion of "Mystic Virtue" actually consists of two parts: "Mystic" and "Virtue". For the former, there are many interpretations throughout history. As 
mentioned, one of the most prevalent is mysteriousness, yet from the study of Shang Y.L. and Zhu C.J., the true meaning of "Mystic" is water, and since "Virtue" is widely accepted to be "virtue", these two together get the connotation as the virtue of water. Water is a pivotal image in Tao Te Ching with its character of nonfighting yet profiting others, yielding yet inscrutable. Thus "Mystic Virtue" is the virtue with features of water, gets far-reading influence, and nurtures things without holding pride and claims its character of humbleness [9].

\section{CONCLUSION}

The political background showed a contribution in the discrepancy in comprehending the same content from different versions of translation. Chinese scholars' interpretation had been acquired for contrasting with chosen English versions for the purpose of seeing how these versions comprehend rather complicated otherculture-based contents. Further, discussions over the relationship between religions and gods, the portrait of the ideal political environment, and the interpretation of the notion "Mystic Virtue" were made for better comprehension. The differentiation in deciphering the chosen content influenced by political backgrounds provides new views in content analysis of lecture translation.

\section{REFERENCES}

[1] Huang, B., Discussion on Minford's English translation of Tao Te Ching, Journal of Yulin Normal University, 2021.

[2] Diao, Y., On cultural confidence in Lin Yutang's English translation of Tao Te Ching, Overseas English, 2018

[3] Zhang, L., Lin Yutang's thick translation of Lao Zi's wisdom, Master Thesis of Southwest, University of Science and Technology, 2015

[4] Chen, G., Lao Tzu annotates and today's translation, The Commercial Press, 2006

[5] B. Boisen, Lao Tzu's Tao Teh Ching: A Parallel Translation Collection, Gnomad Publishing, Boston Massachusetts, 1996

[6] Frederic Henry Balfour. Taoist Texts: Ethical Political and Speculative. Forgotten Books, 2008.

[7] James Legge. Sacred Books of The East. The Oxford University Press, 1879-1910.

[8] Shih, Joseph. "The Notions of God in the Ancient Chinese Religion." Numen, vol. 16, no. 2, Brill, 1969, pp. 99-138, https://doi.org/10.2307/3269759.

[9] Shang Yongliang \& Zhu Chunjie. New Interpretation of "Xuan" and "Xuan De" in Tao Te
Ching. Fudan Journal(Social Sciences), vol. 8, pp.40-47. DOI:CNKI:SUN:FDDX.0.2020-01-005.

[10] Mu-chou, P., Imperial order and local variation: the culture of ghost in early imperial China, Acta Orientalia Academia, 2003

[11] Liu, Y. "Seeing god differently: Chinese piety and European modernity." History of Religions, vol. 45, no. 1, The University of Chicago Press, 2005, pp. 29-44, https://doi.org/10.1086/497815

[12] Shen Siying, Xie Linjie "Socrates' understanding of 'god'." vol. 000, no. 008, 2015, pp. 127, https://wenku.baidu.com/view/ec45fc840812a2161 4791711cc7931b765ce7b8a.html

[13] Zhang Ning, On the crisis of faith and cultural secularization in the Victorian Britain, Literature and Foreign Languages, 2011, G09, B976.3. 10.3963/j.issn.1671-6477.2011.06.026. 